Revista Destaques Acadêmicos, Lajeado, v. 11, n. 1, 2019. ISSN 2176-3070

DOI: http://dx.doi.org/10.22410/issn.2176-3070.v11i1a2019.1870

http://www.univates.br/revistas

\title{
EDUCAÇÃO SUPERIOR E A RENTABILIDADE EMPRESARIAL: UM ESTUDO MULTICASO DAS INSTITUIÇÕES PRIVADAS BRASILEIRAS
}

\author{
Ricardo Viana Carvalho de Paiva ${ }^{1}$, Francisco Vidal Barbosa ${ }^{2}$, \\ Danilo de Melo Costa ${ }^{3}$
}

Resumo: Durante as últimas décadas, o setor da educação superior brasileira, motivado por incentivos do Estado e por uma demanda reprimida da sociedade, cresceu a taxas surpreendentes, atingindo um índice de crescimento de 394\% entre os anos de 1997 à 2007 e movimentando 25 bilhões de reais no ano de 2009. Essa evolução no faturamento, entretanto, não reflete na melhoria dos dados financeiros de todo o setor. Tendo como referência este cenário, o presente estudo tem como objetivo realizar uma análise da rentabilidade empresarial das instituições de educação superior privadas no Brasil, por meio de uma pesquisa multicaso em nove instituições de educação superior nacionalmente reconhecidas. Para tanto, foi realizado um estudo exploratório, de caráter quanti-qualitativo, por meio de coleta de dados em documentos, demonstrações financeiras e realização de entrevistas com executivos nas organizações pesquisadas. Pôde-se evidenciar que embora haja um crescimento e até uma tendência para formação de grandes grupos no setor da educação superior privada, eles também possuem uma série de desafios e, em alguns casos, enfrentam resultados negativos no que se refere à rentabilidade das organizações, algo que deve ser observado por empresários que optem por investir no respectivo setor.

Palavras-chave: Competitividade; Rentabilidade; Desempenho; Educação Superior; Educação Superior Privada

1 Doutor em Administração pela Universidade Federal de Minas Gerais (UFMG). Professor do Programa de Mestrado Profissional em Administração do Centro Universitário Una.

2 Doutor em Competitividade pela Aston University (Inglaterra). Professor Titular da Universidade Federal de Minas Gerais (UFMG).

3 Doutor em Administração pela Universidade Federal de Minas Gerais (UFMG), com doutorado sanduíche pela York University (Canadá). Coordenador e Professor do Programa de Mestrado Profissional em Administração do Centro Universitário Una. 


\section{INTRODUÇÃO}

Durante a década de 70, houve um grande crescimento das instituições de ensino superior privadas, mediante a um incentivo do Estado. Tais instituições passaram a deter a maioria das vagas disponíveis (CANUTO, 1987; GERMANO, 1993). Entre os anos de 1980 à 1996, o setor passou a se desacelerar. A partir de 1997 (até 2007), uma nova expansão é identificada, com o setor atingindo um índice de crescimento de $394 \%$, com a surpreendente média de 17,30\% ao ano (HOPER, 2009). Esta expansão ganhou impulso, em decorrência da sanção da Lei de Diretrizes e Bases da Educação em 1997 (Lei 9394 de 20 de Dezembro de 1996), que flexibilizou as regras para a abertura de cursos e de instituições a partir de 1997. Com isso, houve a permissão para atuação das instituições de ensino como empresas com fins lucrativos a partir de 1998, trazendo diversos empresários para o setor (HADDAD e GRACIANO, 2004; MEYER JUNIOR, 2004).

Além disso, vale à pena destacar a demanda reprimida de jovens até 2002 que não conseguiam vagas nas instituições já existentes, a universalização do ensino fundamental, levando ao crescimento do ensino médio, durante o governo Fernando Henrique Cardoso, a facilitação do acesso ao ensino superior, pois boa parte das pessoas oriundas da população economicamente ativa e que já haviam concluído o ensino médio há cinco anos ou mais ingressou nessa modalidade de ensino e finalmente a redução do valor médio das mensalidades, através do acirramento da competição entre as instituições, o que permitiu o acesso das classes $\mathrm{C}$ e D ao ensino superior privado (SILVA JR e SGUISSARDI, 2001; AMARAL, 2003; MICHELOTTO; COELHO e ZAINKO, 2005; e HOPER, 2009).

Todo este cenário fez com que o setor passasse a ter um alto faturamento, atingindo em 2009 cerca de 25 bilhões de reais, o que o coloca entre os dez maiores setores do país em termos de faturamento. O ano de 2007 também foi marcado pela abertura de capital de instituições de ensino na BMF e BOVESPA, com negócios que atingiram a ordem de 1,3 bilhão de reais. As instituições que atualmente abriram o seu capital foram a Anhanguera Educacional, a Estácio de Sá, a Kroton (Pitágoras) e a SEB. Essas instituições têm utilizado esses recursos provenientes da abertura de capital para ampliarem os seus processos de aquisições, o que têm intensificado ainda mais a competição no setor. Além das instituições de ensino capitalizadas, Lethbridge (2008) apresenta que o setor também tem recebido recursos de fundos de investimentos, como é o caso do UBS Pactual, que possui participação na Fanor (Faculdades Nordeste). Nos últimos anos, a GP Investimentos entrou no setor ao adquirir por 259 milhões de reais uma participação de $20 \%$ no capital da Estácio de Sá, maior universidade privada do país.

Essa evolução no faturamento, entretanto, não reflete na melhoria dos dados financeiros de todo o setor. $\mathrm{O}$ crescimento do número de instituições de ensino privadas foi maior que o crescimento do faturamento do setor, 
promovendo a diluição da receita por instituição, que foi cerca de $R \$ 10,0$ milhões em 2008.

Tendo como premissa o cenário acima, o presente estudo tem como objetivo realizar uma análise da rentabilidade empresarial das instituições de educação superior privadas no Brasil, por meio de uma pesquisa multicaso em nove instituições de educação superior nacionalmente reconhecidas: Centro Universitário UNA, Centro Universitário Unimonte, Centro Universitário UNIBH, Pitágoras (Kroton), Anhanguera, Estácio de Sá, SEB, PUCMINAS e PUCSP. Como justificativa, a escolha das referidas instituições de ensino, torna-se relevante, uma vez que refletem a realidade do setor em questão, constituído por Faculdades (Pitágoras, Estácio, SEB e Anhanguera), Centros Universitários (Una, Unimonte, Uni-BH) e Universidades (PUC MINAS e PUCSP), por Instituições Filantrópicas (PUC MINAS e PUCSP) e Instituições com Fins Lucrativos operadas com capital aberto ou não (UNA, Unimonte, UniBH, Pitágoras, Anhanguera, Estácio de Sá, SEB).

A compreensão da rentabilidade destas instituições oportuniza um mapa da educação superior nacional privada haja vista a amplitude em termos de tradição, representatividade e número de alunos no cenário nacional.

\section{A AVALIAÇÃO DE DESEMPENHO ORGANIZACIONAL SEGUNDO A TEORIA CONTÁBIL}

A avaliação de desempenho organizacional é voltada, de acordo com a Teoria Contábil (STICKNEY e WEIL, 2008), para a análise das atividades operacionais, que estão necessariamente associadas a atividades de compras, produção, marketing e administração. A avaliação do desempenho dessas atividades é feita através das demonstrações financeiras: (1) Balanço Patrimonial; (2) Demonstração do Resultado; (3) Demonstração do Fluxo de Caixa; (4) Notas explicativas às demonstrações financeiras, inclusive tabelas; e (5) Parecer dos auditores externos (IUDÍCIBUS, 1998).

O primeiro, o Balanço Patrimonial, representa um flagrante dos financiamentos e investimentos de uma empresa em determinado instante. Nele, observa-se uma divisão entre duas colunas, a coluna de ativos e a de passivos. O ativo representa os recursos econômicos com capacidade ou potencial que forneçam benefícios futuros. O passivo é o conjunto de direitos que seus credores têm sobre o ativo. O patrimônio líquido é o direito que seus proprietários têm sobre o ativo da empresa. $\mathrm{O}$ ativo é dividido em ativo circulante (de curto ou de longo prazo) e o ativo permanente. O passivo é dividido em passivo circulante e exigível de longo prazo. O patrimônio líquido é composto pelas ações ordinárias e os lucros acumulados (MATARAZZO, 2008).

A segunda demonstração financeira é a Demonstração de Resultado do Exercício (DRE). A DRE tem como objetivo demonstrar o resultado das 
operações realizadas num determinado período. Nela, devem constar os seguintes elementos:

A) a receita bruta das vendas e serviços, as deduções das vendas, os abatimentos e os impostos;

B) a receita líquida das vendas e serviços, o custo das mercadorias e serviços vendidos e o lucro bruto;

C) as despesas com as vendas, as despesas financeiras, deduzidas das receitas, as despesas gerais e administrativas, e outras despesas operacionais;

D) o lucro ou prejuízo operacional, as receitas e despesas não operacionais;

E) o resultado do exercício antes do Imposto sobre a Renda e a provisão para o imposto;

F) as participações de debêntures, empregados, administradores e partes beneficiárias, e as contribuições para instituições ou fundos de assistência ou previdência de empregados;

G) o lucro ou prejuízo líquido do exercício e o seu montante por ação do capital social.

$\mathrm{H})$ as receitas e os rendimentos ganhos no período, independentemente de sua realização em moeda (MARION, 2008).

A terceira demonstração financeira é a Demonstração do Fluxo de Caixa. A Demonstração de Fluxo de Caixa explica as razões pelas quais o saldo de caixa alterou-se entre dois balanços consecutivos (ALVES e MARQUES, 2007). Segundo Stickney e Weil (2008), a demonstração do fluxo de caixa informa um fluxo, enquanto o balanço informa um estoque, ou seja, o saldo em determinado momento. Ela classifica as razões da alteração do saldo de caixa em atividades operacionais, de investimento e de financiamento. As atividades de operações são relacionadas com as receitas provenientes das vendas de bens e prestação de serviços menos os custos de aquisição de bens e serviços.

Analisando ao longo de vários anos, o fluxo de caixa operacional indica a extensão, segundo a qual as atividades têm gerado mais caixa do que têm consumido. As atividades de investimentos estão relacionadas com o caixa recebido pela venda de investimentos e imobilizações menos o caixa pago pela aquisição de investimentos e de imobilizações.

As atividades de financiamento representam a diferença entre o fluxo de caixa recebido pela emissão de debêntures e de ações e o caixa pago pela distribuição de dividendos e pela recompra de ações ou de debêntures. O somatório entre o fluxo de caixa operacional mais o fluxo de caixa de investimentos mais o fluxo de caixa de financiamento é igual à alteração do saldo de caixa do período.

Stickney e Weil (2008) afirmam que a demonstração do fluxo de caixa permite a conciliação entre o lucro líquido e o fluxo de caixa operacional. A 
primeira linha da secção operações do fluxo de caixa mostra o lucro líquido de cada ano, obtido na seção da demonstração de resultado. O regime de contabilização é o de competência. Dessa forma, o fluxo de caixa necessita de ajustes para a conversão do lucro líquido do período, medido em regime de competência, no fluxo de caixa operacional do mesmo período. Para isso, utiliza-se de recursos, dento da conta operacional, tais como a depreciação do lucro líquido. Outro grande ajuste refere-se à alteração nos estoques.

Stickney e Weil (2008) apresentam a equação 1 abaixo para as alterações do saldo de caixa:

\section{(1) $\Delta \mathrm{C}=\Delta \mathrm{P}+\Delta \mathrm{PL}-\Delta \mathrm{AO}$}

Ou seja, a alteração no saldo de caixa é igual à alteração no passivo mais a alteração no patrimônio líquido menos a alteração nos outros ativos.

A quarta Demonstração Financeira é representada pelas tabelas e pelas notas explicativas. Segundo Stickney e Weil (2008), elas têm a função de proporcionar aos avaliadores detalhes adicionais não contemplados nas três demonstrações anteriores. Elas podem conter tabelas com as mutações do patrimônio líquido entre o início e o final do período das demonstrações. As notas explicativas apresentam o método contábil utilizado nas demonstrações, dentre os diversos tipos aceitáveis, além de poderem apresentar outras informações de interesse da empresa.

A quinta Demonstração Financeira é constituída pelo Relatório dos Auditores externos. Ela é exigida para empresas que apresentam ações negociáveis no mercado de capitais. Ela geralmente apresenta três parágrafos. O primeiro relata as demonstrações auditadas e indica que a administração da empresa responsabiliza-se por elas. O segundo parágrafo afirma que o auditor seguiu os princípios de auditoria geralmente aceitos, a menos que algo em contrário seja registrado. O terceiro parágrafo, o mais importante, consiste no parecer, com ou sem ressalvas, sobre a conformidade das demonstrações contábeis aos princípios contábeis geralmente aceitos.

De acordo com a Teoria Contábil (STICKNEY e WEIL, 2008), existem duas abordagens para a mensuração do desempenho operacional: (1) a contabilização pelo regime de caixa e (2) a contabilização pelo regime de competência. Sobre o regime de caixa, a empresa reconhece suas receitas e despesas, quando são efetivamente recebidas e pagas. Esse método apresenta como fragilidades a inadequada confrontação entre despesas e receitas, os atrasos desnecessários no reconhecimento da receita e a possibilidade de manipulação do desempenho operacional. Já a contabilização pelo regime de competência reconhece as receitas e despesas, quando a empresa vende os seus produtos. $\mathrm{O}$ regime de competência fornece melhor medida de desempenho operacional por fazer com que as receitas reflitam mais precisamente os 
resultados da atividade de vendas durante o período analisado e por confrontar mais adequadamente as despesas com as receitas no mesmo período.

Segundo Ross, Westerfield e Jaffe (2002), os índices utilizados para a avaliação das demonstrações financeiras dão informações a respeito de cinco áreas de desempenho financeiro: solvência em curto prazo, atividade, alavancagem financeira, rentabilidade e valor. A primeira mede a capacidade de pagamento de obrigações em curto prazo, a segunda mede a capacidade de gestão dos investimentos em ativos, a terceira mede a proporção de utilização de recursos de terceiros, a quarta mede o nível de lucratividade da empresa e a quinta, o valor da empresa. $\mathrm{O}$ índice rentabilidade, utilizado no presente estudo, é descrito com detalhes próximo tópico.

\section{METODOLOGIA}

A presente pesquisa possui posicionamento epistemológico Funcionalista, norteada pelos pressupostos de Burrel e Morgan (1979). Adicionalmente, possui caráter predominantemente exploratório, de abordagem quanti-qualitativa, realizado inicialmente através da revisão teórica sobre o tema, do levantamento de relatórios, demonstrações financeiras das instituições pesquisadas, publicações sobre o setor de educação e entrevistas com executivos de instituições de ensino superior privadas (MALHOTRA, 2006). Esta prática se fez útil no sentido de identificar estatisticamente a rentabilidade das instituições pesquisadas e confrontar estes dados com a percepção dos gestores participantes.

O presente trabalho adotou a estratégia de multicasos. O tipo de caso adotado foi o projeto holístico de casos múltiplos, uma vez que o estudo adota, como unidades de análise isoladas, nove instituições privadas de ensino superior (YIN, 2005).

A coleta de dados quantitativa se deu meio a documentos disponíveis internamente às empresas estudadas, demonstrações financeiras, relatórios e estatísticas específicas sobre o setor. Também foi adotado o método qualitativo, através da realização de doze entrevistas semiestruturadas com alguns dos principais executivos das empresas analisadas entre os anos de 2009 e 2010, conforme quadro 1:

Quadro 1: Gestores entrevistados

\begin{tabular}{|c|l|l|}
\hline \multicolumn{1}{|c|}{ Instituição } & \multicolumn{1}{|c|}{ Cargo } & \multicolumn{1}{c|}{ Nomeação } \\
\hline \multirow{4}{*}{ Grupo Anima de Educação } & Presidente & Entrevistado 1 \\
\cline { 2 - 3 } & Vice-Presidente de Operações & Entrevistado 2 \\
\cline { 2 - 3 } & Vice-Presidente de Expansão & Entrevistado 3 \\
\cline { 2 - 3 } & Diretora acadêmica & Entrevistado 4 \\
\hline
\end{tabular}




\begin{tabular}{|c|l|l|}
\hline Instituição & \multicolumn{1}{|c|}{ Cargo } & \multicolumn{1}{|c|}{ Nomeação } \\
\hline \multirow{2}{*}{ Centro Universitário UNA } & Reitor & Entrevistado 5 \\
\cline { 2 - 3 } & Vice-Reitor & Entrevistado 6 \\
\hline Centro Universitário Unimonte & Vice-Reitor & Entrevistado 7 \\
\hline Centro Universitário UNIBH & Vice-Reitor & Entrevistado 8 \\
\hline Kroton & Diretor Geral & Entrevistado 9 \\
\hline Anhanguera & Diretor Geral & Entrevistado 10 \\
\hline Estácio de Sá & Coordenador & Entrevistado 11 \\
\hline PUCMINAS & Pró-reitor & Entrevistado 12 \\
\hline PUCSP & \multicolumn{2}{|c|}{ O acesso não foi obtido. } \\
\hline PUCMINAS & \multicolumn{2}{|c}{ O acesso não foi obtido. } \\
\hline
\end{tabular}

Fonte: Elaborado pelos autores.

A saturação teórica, definida por Glaser e Strauss (apud Godoi e Mattos, 2006) ocorreu a partir da quinta entrevista. Entretanto, buscando envolver o máximo de representações das empresas, optou-se por continuar com os demais entrevistados, o que foi útil na confirmação da existência de saturação teórica.

A escolha referidas instituições de ensino, como estudo de caso, torna-se relevante, uma vez que refletem a realidade do setor em questão, constituído por Faculdades, Centros Universitários e Universidades, por Instituições Filantrópicas e Instituições com Fins Lucrativos, por Instituições com capital aberto ou não e por Instituições com operação individualizada ou em rede.

A variável utilizada no método quantitativo para a mensuração dos constructos foi à seguinte:

R: Rentabilidade - Retorno líquido sobre os ativos $(\mathrm{ROA})=$ Lucro líquido / Ativo Total. Fonte: Demonstrações Financeiras dos Centros Universitários.

Para análise das entrevistas, foi utilizada a técnica de Análise de Conteúdo. Visando a cumprir os objetivos do presente trabalho, optou-se pela adoção da Análise de Conteúdo do tipo Categorial Bardin (2009), por compreender que esta melhor adéqua ao posicionamento do trabalho. Os resultados provenientes da análise estatística e das entrevistas são apresentadas na próxima seção.

\section{RESULTADOS DA PESQUISA}

A Rentabilidade $(\mathrm{R}$, dada pelo ROA = Lucro Líquido / Ativo Total) obtida pelas organizações componentes da amostra estudada é representada na Tabela 1. Deve ser ressaltado que quanto maior o índice, maior é a rentabilidade da empresa. Merecem destaque os coeficientes de variação acima de $60 \%$ 
apurado para as organizações Centro Universitário UNA e Estácio de Sá, as únicas a manterem um desempenho positivo em todos os períodos analisados.

Tabela 1 - Estatística descritiva - R

\begin{tabular}{lccccc}
\hline Organização & Mínimo & Máximo & Média & $\begin{array}{c}\text { Desvio- } \\
\text { padrão }\end{array}$ & $\begin{array}{c}\text { Coeficiente de } \\
\text { variação }\end{array}$ \\
\hline Estácio de Sá & 0,06 & 0,24 & 0,12 & 0,08 & 0,61 \\
UNA & 0,04 & 0,15 & 0,08 & 0,05 & 0,64 \\
Kroton & $-0,01$ & 0,15 & 0,06 & 0,07 & 1,12 \\
PUCMINAS & $-0,03$ & 0,04 & 0,01 & 0,03 & 2,42 \\
Anhanguera & $-0,02$ & 0,04 & 0,01 & 0,02 & 3,72 \\
UNIBH & $-0,07$ & 0,00 & $-0,03$ & 0,04 & $-1,26$ \\
PUCSP & $-0,15$ & 0,02 & $-0,05$ & 0,08 & $-1,73$ \\
Unimonte & $-0,23$ & $-0,07$ & $-0,14$ & 0,07 & $-0,51$ \\
SEB & $-11,73$ & 0,16 & $-2,89$ & 5,89 & $-2,04$ \\
\hline
\end{tabular}

Fonte: Elaborado pelos autores.

\subsection{Estácio de Sá}

De acordo com a Tabela 1, a Estácio de Sá apresentou a maior Média de $R(0,12)$, conjuntamente com um Coeficiente de Variação baixo $(0,61)$, comparativamente aos mesmos índices das demais instituições analisadas. Entretanto, mesmo apresentando uma baixa variação, comparativamente, analisando-se o Gráfico 1, observa-se que a perda de rentabilidade para o período foi significativa, partindo-se dos 0,23 em 2006, atingindo 0,97 em 2009. 


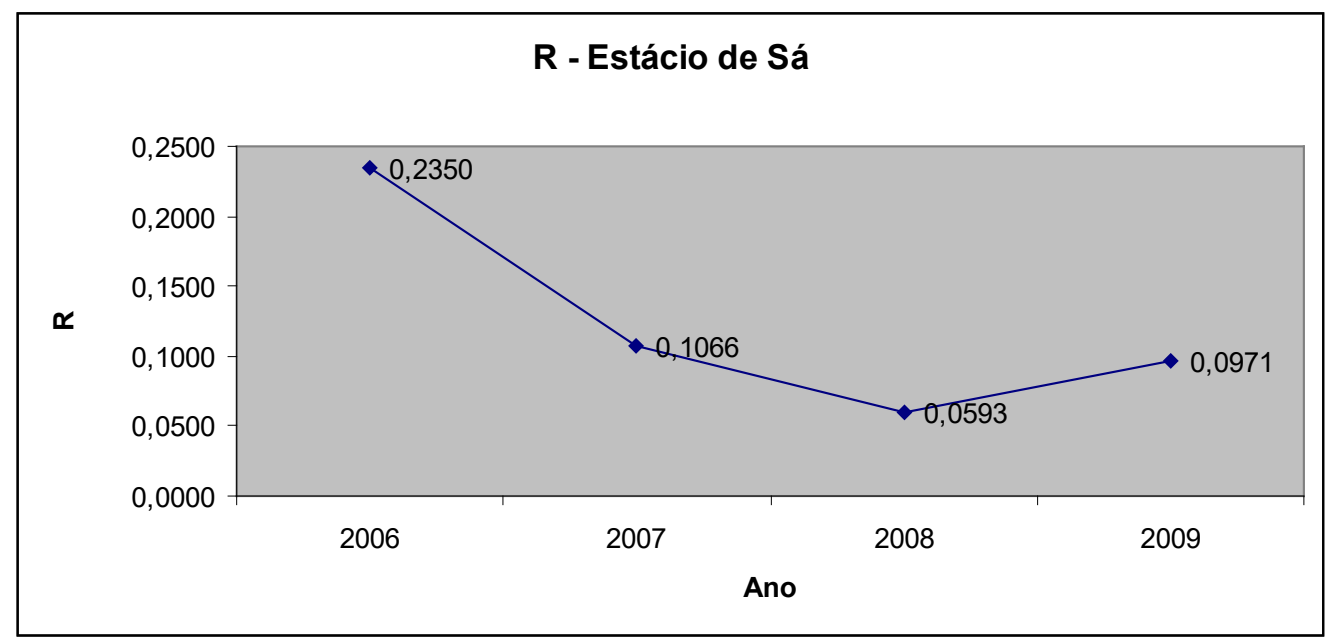

Fonte: Elaborado pelos autores.

De acordo com o Entrevistado 11, esse é um ponto forte da instituição. A abertura de capital na bolsa de valores gerou grandes recursos para a instituição que, praticamente, utiliza somente esse tipo de mecanismo para o financiamento de sua expansão. O nível de alavancagem é muito baixo, os custos são considerados bastante competitivos. O lucro da empresa está na casa dos 30 milhões de reais trimestrais. Não possui problema de solvência e o valor da ação atualmente está em torno de 28 reais com previsão de chegar a 35.

Acho que isso é positivo. É uma forma de financiamento que as grandes instituições estão tendo. A Estácio beneficiou-se muito com esse processo .

A Rentabilidade é muito boa. Por trimestre o lucro deve estar em torno de 30 milhões de reais.

O valor de mercado está em torno de 28 reais. O valor está abaixo do valor esperado. A expectativa é que estaria em torno de 35 (ENTREVISTADO 11).

\subsection{Centro Universitário UNA}

Segundo a Tabela 1, o Centro Universitário UNA apresentou a segunda melhor Média de R, dentre as instituições pesquisadas: 0,08. O seu Coeficiente de Variação foi de 0,64, constituindo um valor relativamente baixo. Diante desses dados e da análise do Gráfico 2, observa-se que a instituição apresentou tendência de melhoria de R, embora haja piora em 2008. A instituição, em 2006, teve um $\mathrm{R}$ de 0,04 e, em 2009, atingiu um $\mathrm{R}$ de 0,15. 


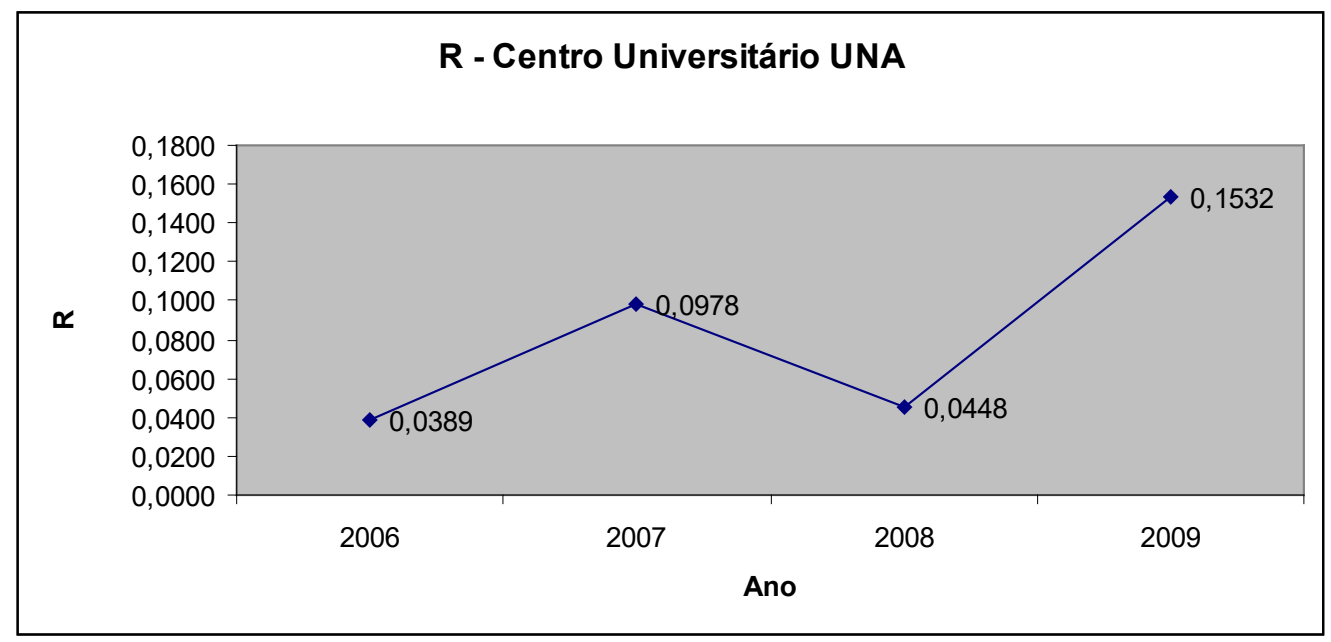

Fonte: Elaborado pelos autores.

O acesso ao mercado de capitais é facilitado para a instituição, em função do resultado financeiro da empresa, cujo nível de rentabilidade é elevado.

A UNA hoje é mais madura, possui resultados mais consistentes, tem acesso melhor a mercados de capitais. Tem uma rentabilidade hoje que acreditamos ser próxima da referência (ENTREVISTADO 2).

Entretanto a instituição tem um nível de alavancagem elevado, parte decorrente da necessidade de capital das outras instituições do grupo, o que pode ser considerado como um ponto negativo para a UNA. Os custos da empresa são considerados pelos entrevistados como competitivos.

\subsection{Króton}

A Kroton obteve a terceira maior Média de $\mathrm{R}(0,06)$ e um Coeficiente de Variação intermediário $(1,12)$, de acordo com a Tabela 1. Tomando-se como referência o Gráfico 3, observa-se que a instituição apresentou tendência de queda em R, partindo de um patamar de 0,15 em 2006 para um valor negativo em 0,01 em 2009. 


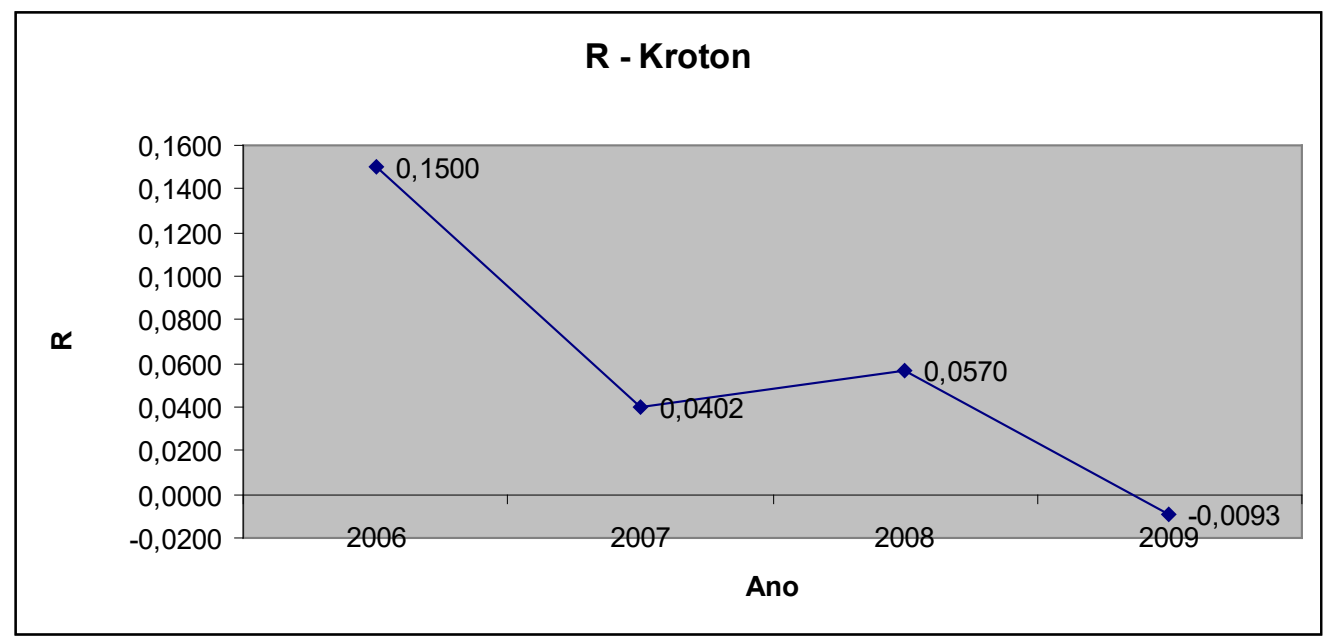

Fonte: Elaborado pelos autores.

Os fatores financeiros são considerados como favoráveis. A empresa utilizou dos recursos provenientes da abertura de capital para o financiamento de sua expansão, reduzindo o seu nível de alavancagem. Os custos são considerados competitivos, derivados dos ganhos de escala. A empresa não tem problema de solvência. $\mathrm{O}$ único aspecto considerado como deficiente é o relacionado à rentabilidade, que o entrevistado julga ser decorrente do processo de expansão do grupo:

Rentabilidade. É baixa, mas em função da maturação das unidades adquiridas. Como fizemos aquisições fortes nos últimos anos, penso que teremos bons resultados nos próximos anos (ENTREVISTADO 9).

O valor de mercado ainda é considerado como abaixo da expectativa da empresa:

Acho que as ações estão abaixo, mas que não refletem o valor real. A projeção é de crescimento, temos o resquício pós-crise (ENTREVISTADO 9).

\subsection{PUCMINAS}

A PUCMINAS apresentou uma Média de $\mathrm{R}$ de 0,01, considerada intermediária, se comparada com as demais Médias da Tabela 1 e um Coeficiente de Variação de 2,42 (em módulo), considerado como elevado, se também comparado aos valores apresentados na Tabela 1. A análise conjunta 
com o Gráfico 4 demonstra uma forte reversão de um quadro negativo de $\mathrm{R}$ em 2006 de $-0,03$ para 0,04 em 2009.

\section{Gráfico 4 - R - PUCMINAS}

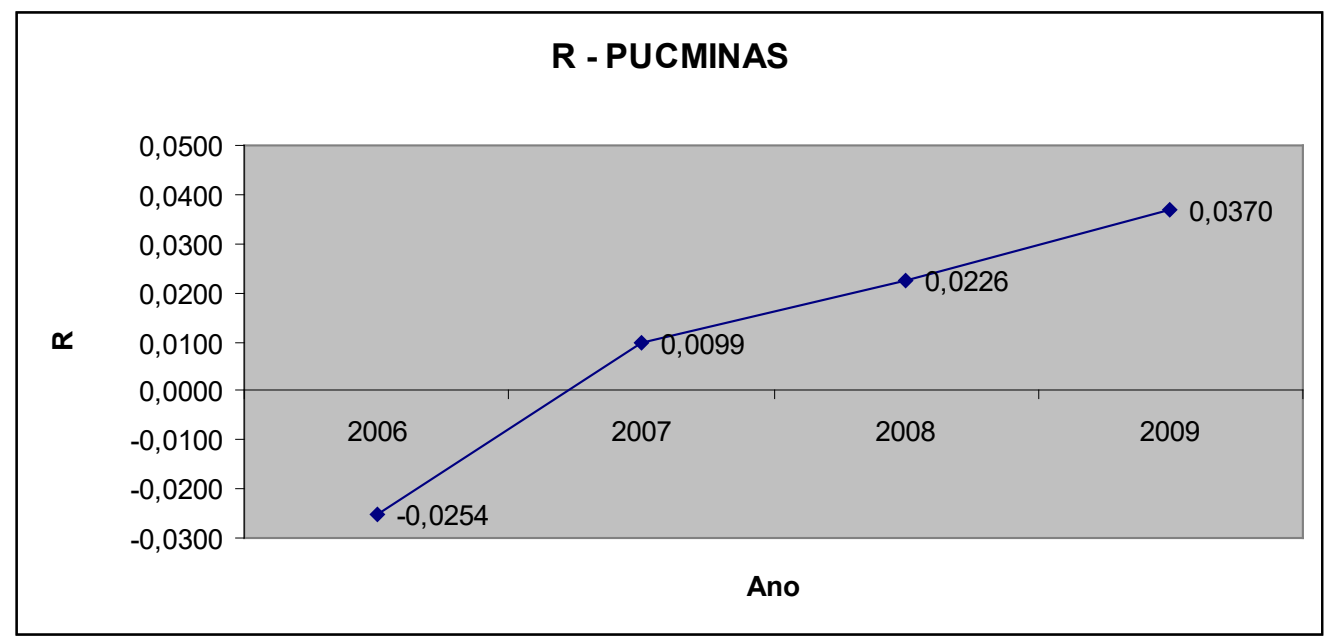

Fonte: Elaborado pelos autores.

A alavancagem é considerada elevada pelo grupo, decorrente do elevado nível de investimentos realizados na última década nas novas unidades, como Contagem, Betim, Arcos, entre outras. Isso afeta o grau de solvência da empresa, apesar de, no plano plurianual, haver a previsão para a amortização dos investimentos. Os custos são considerados elevados, em função da folha de pagamento. Existem também unidades que são deficitárias.

Os custos são muito elevados em função da folha de pagamento que é muito alta. O custo do stricto sensu é muito elevado. Ele é deficitário, apesar do retorno institucional que gera. As unidades deficitárias acabam influenciando a rentabilidade do negócio. No nosso plano plurianual, a amortização disso está bem administrada. Porém o custo da dívida é elevado (ENTREVISTADO 12).

\subsection{Anhanguera}

De acordo com a Tabela 1, a Média de R e o Coeficiente de Variação da Anhanguera foram de 0,01 e de 3,72, respectivamente. O primeiro índice representa um valor intermediário, enquanto o segundo é o de maior valor, dentre as instituições pesquisadas. O Gráfico 5 demonstra que o seu R sofreu grandes oscilações no período, partindo de um valor praticamente nulo em 2006, passando por um valor negativo em 0,02 em 2008 e alcançando um valor positivo em $0,04 \mathrm{em} 2009$. 
Gráfico 5 - R - Anhanguera

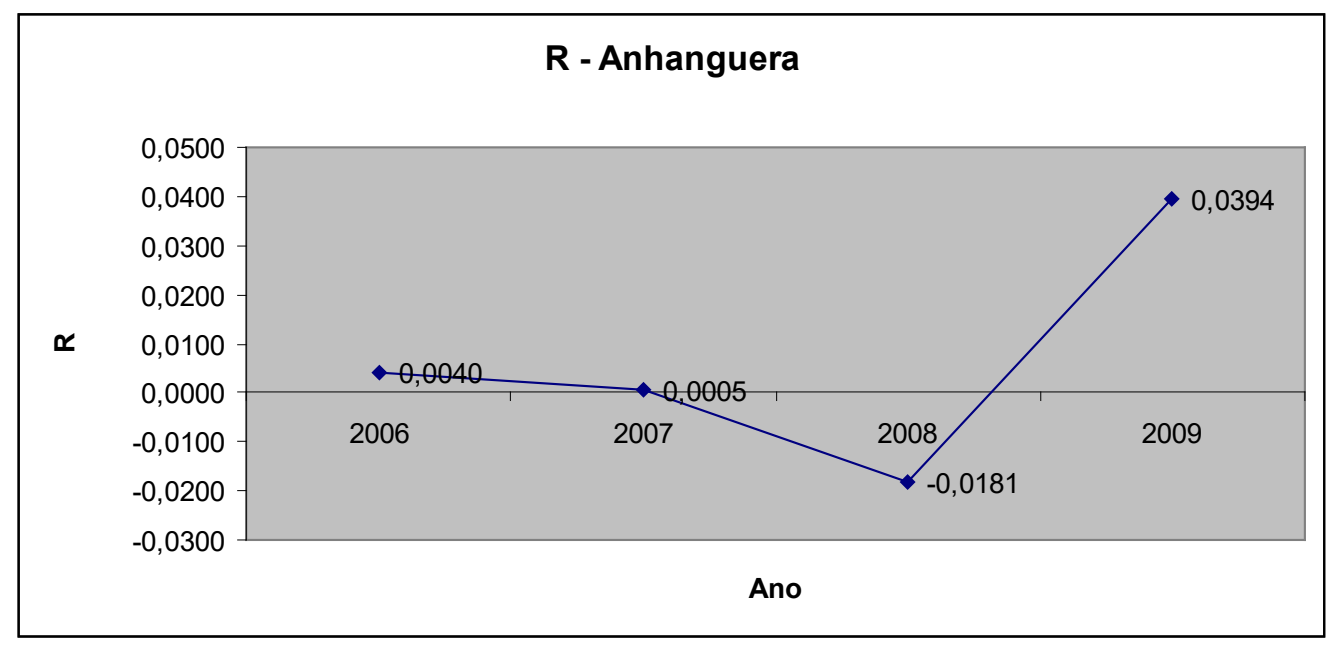

Fonte: Elaborado pelos autores.

Considera-se que o bom resultado financeiro da empresa acaba por atrair investimentos no mercado de ações, que por sua vez, contribui para o seu crescimento:

Para uma instituição que tem ação na bolsa, como é o caso da Anhanguera, isso faz toda a diferença. Acho que é todo um ciclo. Uma empresa com um bom balanço acaba por atrair mais capitais, para isso tem que ter custos competitivos, uma boa atividade, boa solvência (ENTREVISTADO 10).

\subsection{Centro Universitário UNIBH}

O Centro Universitário UNIBH, diante da Tabela 1, apresentou uma Média de $\mathrm{R}$ negativa em $-0,03$, considerado um valor intermediário diante das demais Médias e um Coeficiente de Variação de 1,26, também intermediário. De acordo com o Gráfico 6, observa-se tendência acentuada de queda no $\mathrm{R}$ entre 2006 e 2008, atingindo neste último o seu pior resultado: -0,07. Entre 2008 e 2009, o gráfico demonstra reversão, atingindo um R de -0,04 em 2009. 


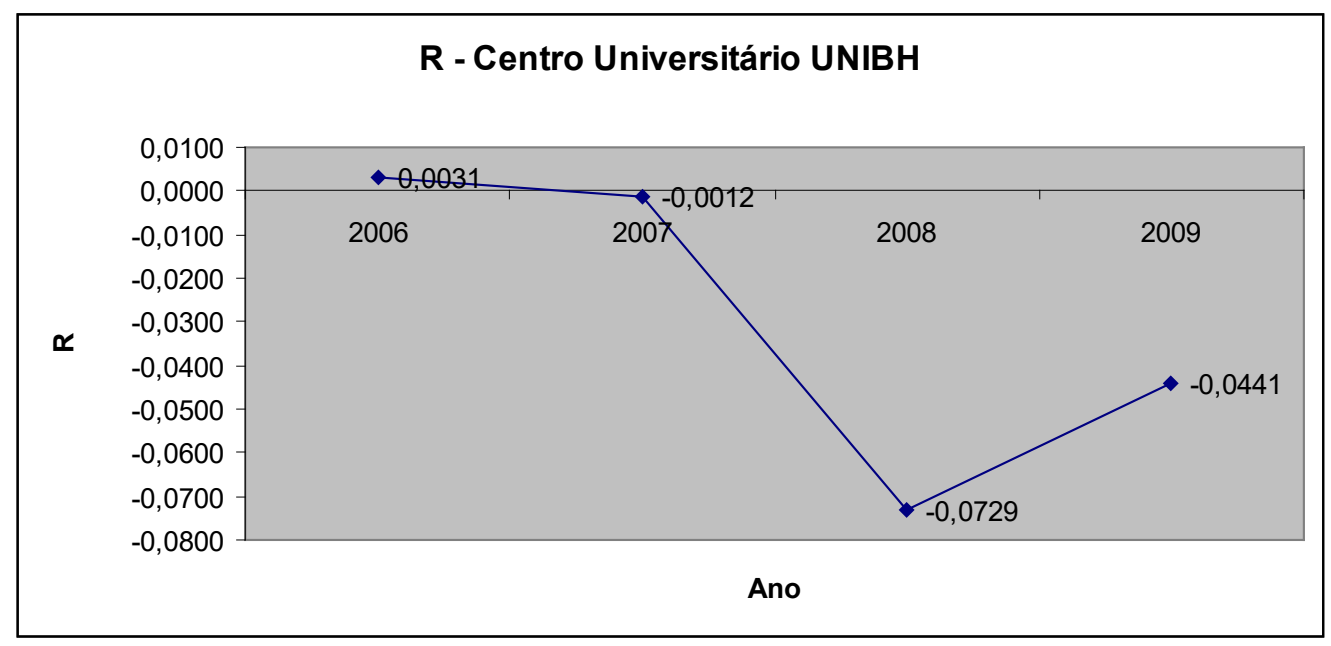

Fonte: Elaborado pelos autores.

De acordo com os entrevistados, a empresa teve uma crise de solvência que culminou com a sua venda no ano de 2009. O nível de alavancagem era muito elevado, a atividade era baixa, os custos elevados a patamares que tornavam a empresa pouco competitiva. O nível de rentabilidade era baixo. $\mathrm{O}$ acesso ao mercado de capitais era restrito. Com o novo grupo controlador, esses fatores têm melhorado, reflexo do processo de reestruturação.

\subsection{PUCSP}

Para a PUCSP, a Tabela 1 sugere uma Média de R de $-0,05$, o terceiro menor resultado dentre as instituições analisadas. O seu Coeficiente de Variação ficou em 1,73, considerado intermediário diante do mesmo índice das demais instituições. O Gráfico 7 demonstra reversão de um quadro negativo de rentabilidade, partindo de um valor em 2006 de -0,15, atingindo um $\mathrm{R}$ de 0,02 em 2009, o que demonstra uma importante reversão de uma situação desfavorável para a instituição. 


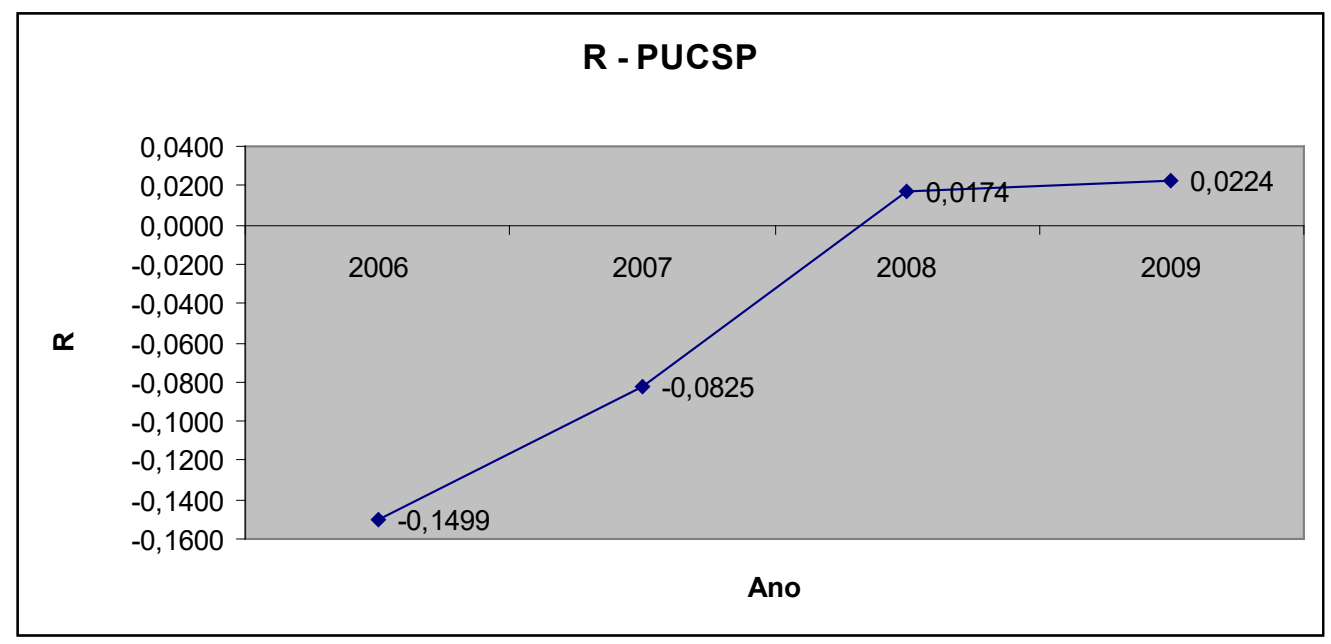

Fonte: Elaborado pelos autores. concedida.

A permissão para a realização de entrevistas nessa instituição não foi

\subsection{Centro Universitário Unimonte}

O Centro Universitário Unimonte apresentou uma baixa Média de $\mathrm{R}$ para o período analisado $(-0,14)$ assim como um baixo Coeficiente de Variação $(0,51)$. Esses resultados, analisados conjuntamente com o Gráfico 8, demonstram que a empresa conseguiu diminuir uma situação desfavorável de rentabilidade negativa de -0,23 em 2006 para um patamar de -0,12 em 2009. Entretanto essa reversão foi pequena diante do cenário desfavorável apresentado no período. Entre 2008 e 2009, a instituição ainda apresentou piora no índice, partindo de um $R$ de $-0,07$ para um $R$ de 0,12 . 


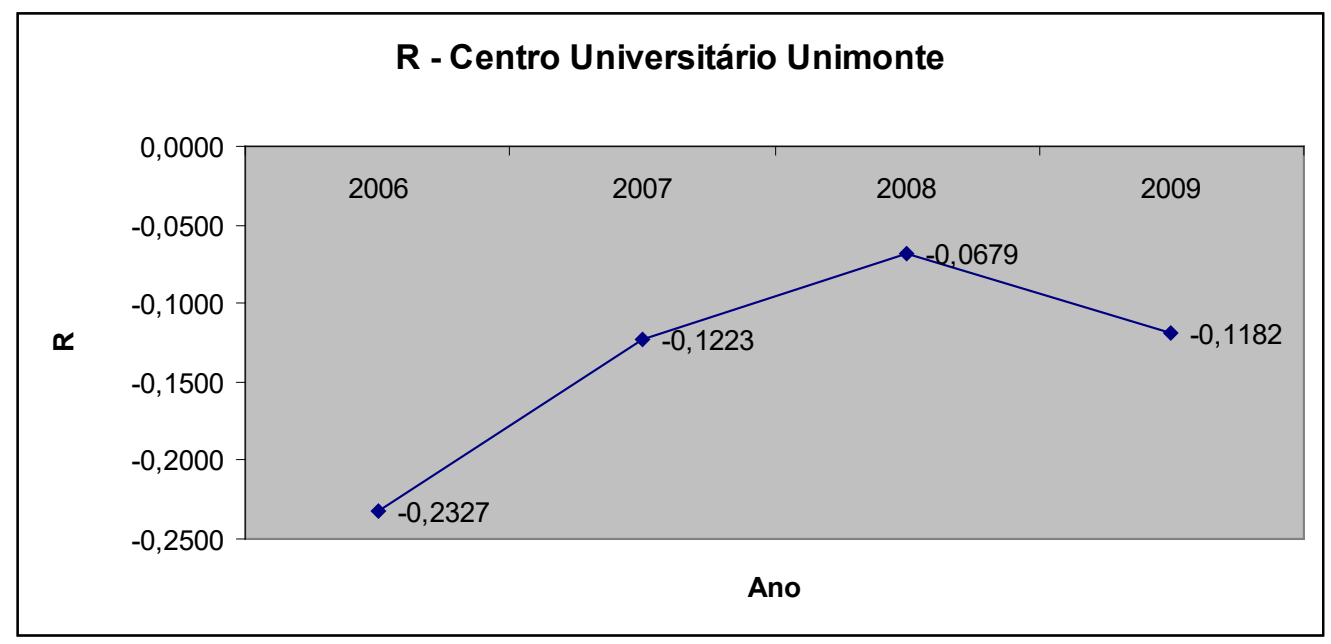

Fonte: Elaborado pelos autores.

$\mathrm{O}$ acesso a fontes de financiamento diretamente para a instituição ainda é restrito, em função da sua situação financeira:

A Unimonte está em uma fase de reestruturação, com dúvidas de se será positiva. $\mathrm{O}$ mercado de capitais ainda tem restrições, a rentabilidade é negativa (ENTREVISTADO 3).

O nível de alavancagem é muito elevado:

É alto, da ordem de $40 \%$ da receita, pois estamos pagando coisas passadas que não haviam sido pagas pela antiga gestão. Isso complica $\mathrm{o}$ acesso a financiamento e a possibilidade de investimento em outras coisas importantes para a instituição (ENTREVISTADO 7).

O custo do negócio ainda não consegue ser competitivo, em função das condições do mercado local. A guerra de preço, por sua vez, também afeta a rentabilidade do negócio:

O custo é preponderante, pois já estamos no limite para podermos concorrer com a guerra de preço (ENTREVISTADO 7).

A instituição foi vendida em 2007 para o atual grupo controlador, por problemas de solvência. Desde então, uma grande reestruturação foi implementada, o que melhorou os indicadores financeiros, porém sem conseguir atingir um nível de rentabilidade adequado. 


\subsection{SEB}

A SEB, de acordo com a Tabela 1, apresentou a menor Média de $\mathrm{R}(-2,89)$ e o segundo maior Coeficiente de Variação (2,42 em módulo). Diante do Gráfico 9, constata-se que a empresa saiu de um forte resultado negativo em 2006, que pode ser explicado pelo início das operações da empresa para valores positivos e expressivos nos anos de 2007, 2008 e 2009, atingindo um R no último ano de análise de 0,16.

Gráfico 9 - R - SEB

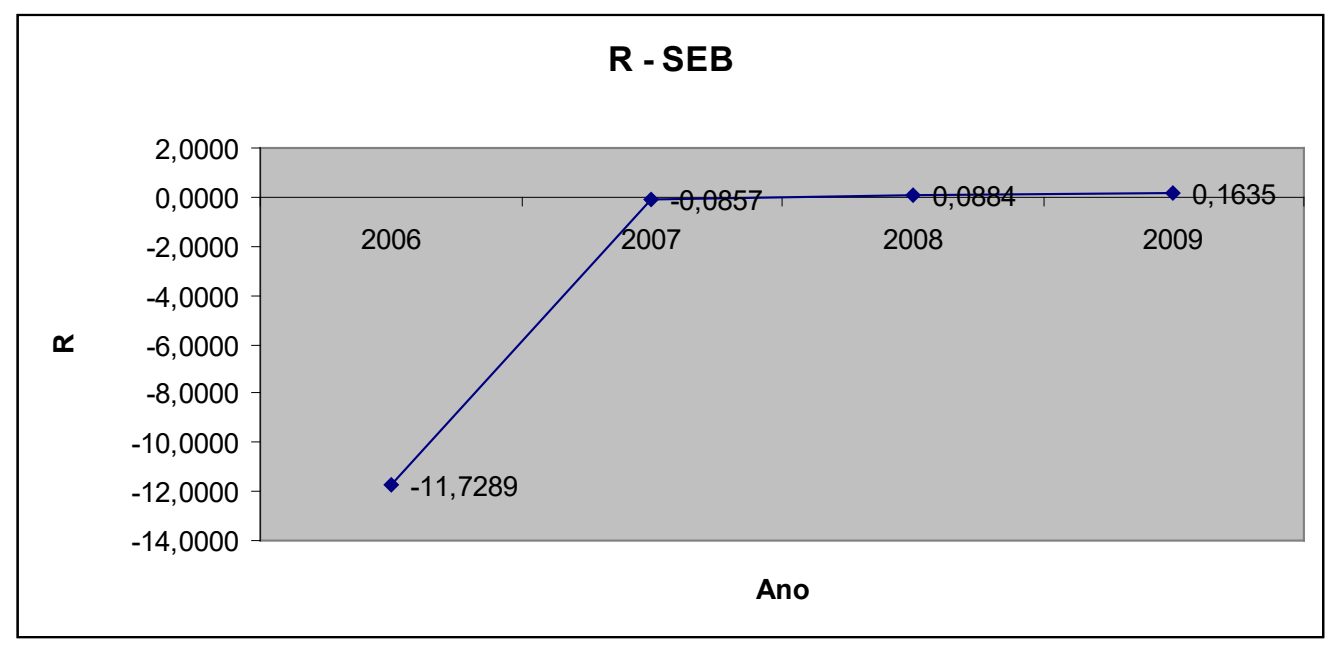

Fonte: Elaborado pelos autores.

A permissão para a realização de entrevistas nessa instituição não foi concedida.

\section{CONSIDERAÇÕES FINAIS}

O presente estudo realizou uma análise da rentabilidade empresarial das instituições de educação superior privadas no Brasil, por meio de uma pesquisa multicaso em nove instituições de educação superior nacionalmente reconhecidas: Centro Universitário UNA, Centro Universitário Unimonte, Centro Universitário UNIBH, Pitágoras (Kroton), Anhanguera, Estácio de Sá, SEB, PUCMINAS e PUCSP.

No que se refere à pesquisa quantitativa, a análise do indicador R: Rentabilidade - Retorno líquido sobre os ativos (ROA) $=$ (Lucro líquido / Ativo Total), pode-se comprovar que a maior parte das empresas pesquisadas enfrentou momentos de baixa rentabilidade no período pesquisado, com exceção das organizações Centro Universitário UNA e Estácio de Sá, que tiveram os coeficientes de variação acima de $60 \%$ apurado para as organizações 
e foram as únicas a manterem um desempenho positivo em todos os períodos analisados.

Entretanto, a pesquisa qualitativa pode confrontar os achados quantitativos, explicando com mais profundidade os momentos de alta e baixa rentabilidade de cada organização. Ainda no que tange a pesquisa qualitativa, as instituições Centro Universitário UNA, Kroton, Anhanguera e Estácio de Sá tiveram, no depoimento dos entrevistados, os Fatores Financeiros apontados como favoráveis às mesmas. Por outro lado, o Centro Universitário UNIBH, o Centro Universitário Unimonte e a PUCMINAS, tiveram esses aspectos apresentados como insatisfatórios pelos entrevistados. As instituições PUCSP e SEB não participaram da etapa qualitativa.

Pôde-se evidenciar que embora haja um crescimento e até uma tendência para formação de grandes grupos no setor da educação superior privada (segundo Hoper (2009), até 2015 mais de 50\% do mercado pertencerá a um grupo de no máximo 17 empresas), eles também possuem uma série de desafios e, em alguns casos, enfrentam resultados negativos no que se refere à rentabilidade das organizações.

Em conclusão, por ser um cenário altamente competitivo e que passa por diversas transformações, recomenda-se aos investidores do setor que analisem com prudência os resultados das instituições, sobretudo a rentabilidade e o desempenho, e optem por aquelas que se apresentarem mais consistentes financeiramente.

\section{REFERÊNCIAS}

ALVES, Luis C.O.e MARQUES, José Augusto V.C. Identificação das Fases do Ciclo de Vida de Empresas através da Análise das Demonstrações dos Fluxos de Caixa. Revista Base de Administração e Contabilidade da Unisinos. 2007.

AMARAL, Nelson C. Financiamento da Educação Superior: Estado X Mercado. Ed. UNIMEP, São Paulo. 2003.

BURRELL, G.; MORGAN, G. Social Pradigms and Organisational Anaysis: Elements of the Sociology of Corporate Life. London: Heinemann, 1979.

CANUTO, Vera Regina Albuquerque. Políticos e Educadores: a organização do ensino superior no Brasil. Petrópolis: Editora Vozes. 1987.

GERMANO, J. W. Estado Militar e Educação no Brasil (1964-1985). São Paulo: Cortez Ed. Unicamp. 1993.

HADDAD, Sérgio and GRACIANO, Mariângela. Educação: direito universal ou mercado em expansão. São Paulo em Perspectiva. Vol.18, n.3, p. 67-77, 2004.

HOPER. Análise Setorial do Ensino Superior Privado-Brasil. Foz do Iguaçu, 2009. 
IUDÍCIBUS, Sérgio de. Contabilidade Gerencial. 6 ed. São Paulo: Atlas, 1998.

LETHBRIDGE, T. Americanos oferecem R \$2,5 bilhões pelo Objetivo. Exame, São Paulo, 18 jun. 2008. Disponível em: <http:/ / exame.abril.com.br/negocios/empresas / noticias / americanos-oferecem-r-2-5-bilhoes-pelo-objetivo-m0162280>.Acesso em: 09 de Dezembro 2012).

MALHOTRA, N. Pesquisa de Marketing: uma orientação aplicada. Porto Alegre: Bookman, 2006.

MARION, José Carlos. Contabilidade Empresarial. 13 ed. São Paulo: Atlas, 2008.

MATARAZZO, Dante Carmine. Análise Financeira de Balanços: Abordagem Básica e Gerencial. 6 ed. São Paulo: Atlas, 2008.

MEYER JUNIOR, V. Planejamento Estratégico: Ato Racional, Político ou Simbólico - Um Estudo das Universidades Brasileira. In: Anais do XXVIII Encontro Anual da ANPAD, 2004, Curitiba, PR. Anais. Curitiba: ANPAD. 2004.

MICHELOTTO, R. M.; COELHO, R. H.; ZAINKO, M. A. S. A política de expansão da educação superior e a proposta de reforma universitária do governo Lula. Revista Educar, Curitiba, n. 28, p. 179-198. Editora UFPR. 2006.

ROSS, S.A.; WESTERFIELD, R.W.; JAFFE, J.F. Administração financeira. São Paulo: Atlas, 2002.

SILVA JR, João dos Reis; SGUISSARDI, Valdemar. Novas faces da educação superior no Brasil. 2. Ed. Bragança Paulista, SP: USF-IFAN. 2001.

STICKNEY, C.P, WEIL, R. Contabilidade Financeira: uma introdução aos conceitos, métodos e usos. São Paulo: Atlas, 2008.

YIN, R.K. Estudo de caso: planejamento e métodos. Porto Alegre: Bookman, 2005. 